INFECTION CONTROL AND HOSPITAL EPIDEMIOLOGY NOVEMBER 2007, VOL. 28, No. 11

\title{
Determinants of Good Adherence to Hand Hygiene Among Healthcare Workers Who Have Extensive Exposure to Hand Hygiene Campaigns
}

\author{
Hugo Sax, MD; Ilker Uçkay, MD; Hervé Richet, MD; Benedetta Allegranzi, MD; Didier Pittet, MD, MS
}

овJECTIVE. To quantify the different behavioral components of healthcare workers' motivation to comply with hand hygiene in a healthcare institution with a 10 -year history of hand hygiene campaigning.

DESIGN. Cross-sectional study, by use of an anonymous, self-administered questionnaire.

SETTING. A 2,200-bed university teaching hospital.

PARTICIPANTs. A stratified random sample of 2,961 medical and nursing staff.

RESULTS. A total of 1,042 questionnaires (35.2\%) were returned. Of the respondents, $271(26.0 \%)$ were physicians, $629(60.4 \%)$ were nurses, and 141 (13.5\%) were nursing assistants. Overall, 1,008 respondents provided information about sex; 718 (71.2\%) of these were women. Respondents provided demographic information and data about various behavioral, normative, and control beliefs that determined their intentions with respect to performing hand hygiene. Among behavioral beliefs, the perception that healthcare-associated infections are severe for patients was highly ranked as a determinant of behavior by $331(32.1 \%)$ of the respondents, and the perception that hand hygiene is effective at preventing these infections was ranked highly by 891 respondents ( $86.0 \%)$. Among normative beliefs, perceived social pressure from patients to perform hand hygiene was ranked highly by 760 respondents (73.7\%), pressure from superiors was ranked highly by $687(66.8 \%)$, pressure from colleagues was ranked highly by $596(57.9 \%)$, and pressure from the person perceived to be most influential was ranked highly by $687(68.8 \%)$. Among control beliefs, the perception that hand hygiene is relatively easy to perform was rated highly by 670 respondents $(65.1 \%)$. High self-reported rates of adherence to hand hygiene (defined as performance of proper hand hygiene during $80 \%$ or more of hand hygiene opportunities) was independently associated with female sex, receipt of training in hand hygiene, participation in a previous hand hygiene campaign, peer pressure from colleagues, perceived good adherence by colleagues, and the perception that hand hygiene is relatively easy to perform.

CONCLUSIONS. In a setting with a long tradition of hand hygiene campaigns, behavioral beliefs are strongly in favor of hand hygiene, but adherence is driven by peer pressure and the perception of high self-efficacy, rather than by reasoning about the impact of hand hygiene on patient safety. Female sex, training, and campaign exposure increased the likelihood of compliance with hand hygiene. This additional insight can help to shape future promotional activity.

Infect Control Hosp Epidemiol 2007; 28:1267-1274

Hand hygiene is recognized as a primary determinant of the incidence of healthcare-associated infection and the crosstransmission of nosocomial pathogens, but compliance rates among healthcare workers (HCWs) are often less than $40 \%{ }^{1}$ Multimodal interventions have the greatest chance of successfully improving adherence to practices. ${ }^{2}$ As in many other health-related areas, beliefs, attitudes, and perceptions influence HCWs' hand hygiene behavior. However, the inability to achieve sustained, high-quality performance of hand hygiene suggests that changing this behavior is complex. ${ }^{3,4}$ Rather than taking an empirical approach to improve hand hygiene adherence, we might seek insight into the motiva- tional factors driving this behavior, to shape further promotional interventions and obtain better outcomes. ${ }^{3}$

The Theory of Planned Behavior ${ }^{5}$ is the most widely applied model in which attitudes, subjective norms, and perceived behavioral control combine to predict a given behavioral intention and, thus, a given behavior. The theory has already been applied to hand hygiene behavior, with some success. ${ }^{3,6,7}$ In brief, the model postulates that the intention to perform hand hygiene is influenced by 3 separate factors and their belief antecedents: (1) beliefs about outcomes produce a favorable or unfavorable attitude towards hand hygiene (attitude), (2) beliefs about the expectations of others who are

From the Infection Control Program, University of Geneva Hospitals (H.S., I.U., D.P.), and the Global Patient Safety Challenge, World Health Organization (WHO) World Alliance for Patient Safety, WHO Headquarters (H.R., B.A., D.P.), Geneva, Switzerland.

Received March 23, 2007; accepted July 11, 2007; electronically published September 6, 2007.

(C) 2007 by The Society for Healthcare Epidemiology of America. All rights reserved. 0899-823X/2007/2811-0009\$15.00. DOI: 10.1086/521663 
perceived as important lead to social pressure to perform hand hygiene (subjective norm), and (3) control beliefs give rise to perceived behavioral control. Intention therefore translates into action that can be assessed by direct observation of hand hygiene, the consumption of hand hygiene products, or self-reported adherence. Demographic factors and previous life experiences help to form personal beliefs and represent the most distal component of the model. We performed a large-scale survey of HCWs' experiences and the perceived cognitive antecedents of hand hygiene behavior to identify the relevant internal and external motivational factors that lead to better hand hygiene among individuals in different professional categories.

\section{METHODS}

\section{Setting}

The University of Geneva Hospitals (Geneva, Switzerland) include a 2,200-bed primary and tertiary care university hospital that serves a population of approximately 800,000 and has 47,000 admissions annually. In 2005, there were approximately 10,000 employees, which included 1,490 physicians, 3,328 nurses, and 1,103 nursing assistants. Beginning in 1995, staff members in the acute care sectors were exposed to a multimodal hand hygiene promotion campaign ${ }^{2}$ that later became a template ${ }^{8}$ for many other similar campaigns worldwide. ${ }^{1,2,7,-12}$ Since 1994, alcohol-based hand rub has been widely available to staff in the form of pocket-sized bottles, and it is used almost exclusively throughout the hospital as the agent of choice for hand hygiene. ${ }^{2}$ In 2003, a program applying a social marketing strategy was initiated for homogeneous implementation of standard precautions and isolation precautions under the registered trademark of VigiGerme. Hand hygiene was once again promoted as an element of standard precautions. This program was ongoing at the time of the present study.

\section{Participants and Sampling Strategy}

The study was conducted in October 2005, and it targeted physicians, nurses, and nursing assistants. We selected a random sample from each professional category by using a coin toss to select one of two HCWs from each pair of names on an alphabetical list. Of 5,921 eligible staff, 2,961 received a self-administered paper questionnaire at their workplace by internal mail. An envelope was supplied for anonymous return to the infection control program by internal mail. A reminder to respond was sent to all participants 2 weeks after distribution. The institutional review board approved the study as part of the infection control quality improvement program; signed informed consent was not judged necessary.

Questionnaire design and data collection. We followed guidelines from social cognitive theories applied to healthrelated behaviors ${ }^{13-15}$ in the construction of the questionnaire, notably the Theory of Planned Behavior. ${ }^{16}$ Most questions were drawn from questionnaires used previously in our institution. ${ }^{7,17,18}$ The questions and their relation to the Theory of Planned Behavior model are shown in the Figure. The questionnaire was pilot tested with 120 respondents before it received final approval.

Experienced technicians performed data entry by use of character recognition scanning hardware and software (TeleForm; Cardiff). Conflicting results were checked manually and corrected or entered as missing values, as appropriate.

Data analysis. As described elsewhere, ${ }^{7}$ we assessed the demographic characteristics and cognitive factors associated with self-reported adherence to hand hygiene (Figure) by using single choice item lists and 7-point Likert scales. The last 2 points of the scale closest to the positive evaluation of the perspective in the item were considered positive responses; all other points were classified as negative responses. ${ }^{7,19}$ Univariate analysis was performed with Epi Info software, version 3.3.2 (Centers for Disease Control and Prevention). Proportions were compared by use of the Yates $\chi^{2}$ correction or the Fisher exact test; continuous variables were compared by use of either analysis of variance or the Mann-Whitney $U$ test, or by use of the Wilcoxon 2-sample test when the data were not normally distributed.

For multivariate analysis, a model was designed to measure the independent role played the following factors: sex; age greater than $\mathbf{4 0}$ years; staff level; years at the institution; training in hand hygiene; participation in a previous hand hygiene campaign; having been observed for hand hygiene adherence; perception of the severity of healthcare-associated infections; perception of the efficacy of hand hygiene; the perceived expectations with respect to hand hygiene of superiors, colleagues, patients, and the person believed to be most influential; the perceived priority of hand hygiene for senior management; the perceived adherence of colleagues; the perceived effect of setting a good example for others; and the effort required to perform hand hygiene. The outcome variable was self-reported good hand hygiene adherence, defined as performance of proper hand hygiene during $80 \%$ or more of hand hygiene opportunities. Additionally, separate multivariate analyses were performed for nurses, nursing assistants, and physicians. Binary logistic regression analyses were performed with SPSS software, version 10 (SPSS).

\section{RES U L T S}

Of 2,961 questionnaires, $1,042(35.2 \%)$ were returned. The return rate was similar for physicians (36.4\% [271 of 745]) and nurses $(37.8 \%$ [629 of 1,664$])$ but lower for nursing assistants (25.5\% [141 of 552]). A total of 1,008 respondents provided information about sex, of which $290(28.8 \%)$ were male (question 1). Four hundred fifty-two (43.6\%) of the respondents were more than 40 years old (question 2). A total of $271(26.0 \%)$ were physicians, $629(60.4 \%)$ were nurses, and $141(13.5 \%)$ were nursing assistants (question 3). Stratification by staff level showed that $79(8.2 \%)$ of the respondents were senior staff members, 154 (15.9\%) were inter- 


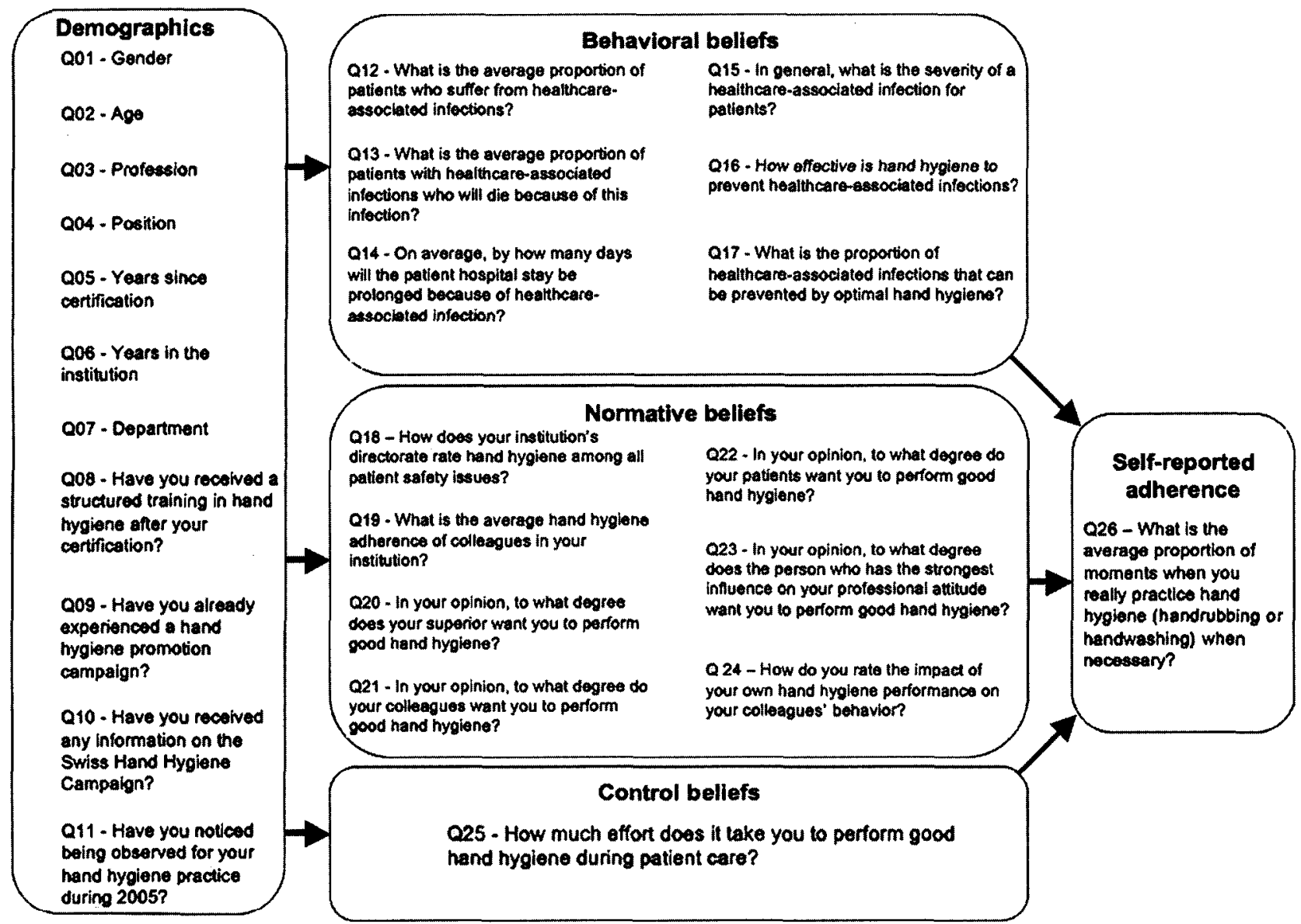

FIGURE. Questionnaire content and applied cognitive behavior model in relation to the Theory of Planned Behavior. The questionnaire was distributed to healthcare workers at the University of Geneva Hospitals, October 2005, and the cognitive behavior model was adapted from Conner and Norman. ${ }^{13}$

mediate-level staff, and $736(76.0 \%)$ were junior-level staff (question 4). For physicians, the junior, intermediate, and senior staff levels correspond to intern, resident, and attending physician, respectively. For nurses, these staff levels correspond to registered ward nurse, charge nurse, and nurse manager, respectively.

Of 1,030 respondents who provided information about duration of professional experience, $579(56.2 \%)$ reported more than 10 years of experience (question 5); of the 1,039 respondents who reported their years of experience at this institution, 409 (39.4\%) reported more than 10 years (question 6). A total of 994 respondents provided information about their departments; the departmental distribution of respondents was as follows: gynecology-obstetrics, 42 respondents $(4.2 \%)$; intensive care unit, $95(9.6 \%)$; internal medicine, 153 (15.4\%); surgery, 104 (10.5\%); outpatient clinics, 77 (7.8\%); pediatrics, $122(12.3 \%)$; psychiatry, $155(15.6 \%)$; radiology, 23 (2.3\%); rehabilitation, 132 (13.3\%); and others, 91 (9.2\%) (question 7). Familiarity with hand hygiene practices was indicated by 780 respondents $(75.5 \%)$, who reported having received formal training in hand hygiene (question 8). A total of $786(76.8 \%)$ reported participation in a previous hand hygiene promotion campaign (question 9), and 134 (13.3\%) had already heard about the Swiss Hand Hygiene Campaign (question 10). Furthermore, $205(20.0 \%)$ recalled having been observed for their adherence to hand hygiene practices during 2005 (question 11).

Table 1 shows HCWs' beliefs about the frequency, severity, and impact of healthcare-associated infections, as well as their beliefs about the perceived effectiveness of hand hygiene, perceived social pressure, and perceived self-efficacy. Overall, $52.3 \%$ of respondents perceived the percentage of patients with healthcare-associated infections to be greater than 15\%; this was true for $46.1 \%$ of physicians, $52.7 \%$ nurses, and $62.5 \%$ nursing assistants. Compared with individuals from the other professional categories, a greater percentage of nurses believed that healthcare-associated infections result in prolonged hospital stays, that good hand hygiene adherence can prevent a significant percentage of healthcare-associated infections, and that healthcare-associated infections have se- 
TA B LE 1. Healthcare Workers' Beliefs About Healthcare-Associated Infections (HAIs) and Hand Hygiene Adherence, According to Professional Category, University Hospitals of Geneva, October 2005

\begin{tabular}{|c|c|c|c|c|c|}
\hline \multirow[b]{2}{*}{ Belief area, question number, item } & \multicolumn{4}{|c|}{ No. (\%) of respondents } & \multirow[b]{2}{*}{$P$} \\
\hline & $\begin{array}{l}\text { Physicians } \\
(n=271)\end{array}$ & $\begin{array}{c}\text { Nurses } \\
(n=629)\end{array}$ & $\begin{array}{l}\text { Nursing } \\
\text { assistants } \\
(n=141)\end{array}$ & $\begin{array}{c}\text { Overall } \\
(N=1,042)\end{array}$ & \\
\hline \multicolumn{6}{|l|}{ Behavioral } \\
\hline \multicolumn{5}{|l|}{ 12: Percentage of patients with HAIs } & $<.001$ \\
\hline $0 \%-10 \%$ & $91(33.6)$ & $192(30.9)$ & $37(27.2)$ & $320(31.1)$ & \\
\hline $11 \%-20 \%$ & $116(42.8)$ & $204(32.8)$ & $34(25.0)$ & $354(34.4)$ & \\
\hline$>20 \%$ & $64(23.6)$ & $226(36.3)$ & $65(47.8)$ & $355(34.5)$ & \\
\hline \multicolumn{5}{|l|}{ 13: Mortality rate among infected patients } & .25 \\
\hline $0 \%-2 \%$ & $82(30.4)$ & $206(33.3)$ & $52(39.7)$ & $340(33.4)$ & \\
\hline $3 \%-5 \%$ & $77(28.5)$ & $189(30.6)$ & $39(29.8)$ & $305(29.9)$ & \\
\hline$>5 \%$ & $111(41.1)$ & $223(36.1)$ & $40(30.5)$ & $374(36.7)$ & \\
\hline \multicolumn{5}{|l|}{ 14: Extra length of hospital stay for infected patients } & .001 \\
\hline $0-10$ days & $122(45.2)$ & $198(32.1)$ & $55(40.7)$ & $375(36.7)$ & \\
\hline $11-20$ days & $98(36.3)$ & $237(38.4)$ & $46(34.1)$ & $381(37.3)$ & \\
\hline$>20$ days & $50(18.5)$ & $182(29.5)$ & $34(25.2)$ & $266(26.0)$ & \\
\hline 15: HAIs are severe for patients & $67(24.9)$ & $217(34.8)$ & $47(33.6)$ & $331(32.1)$ & .01 \\
\hline 16: Good hand hygiene effectively prevents infections & $209(77.7)$ & $566(90.4)$ & $116(82.3)$ & $891(86.0)$ & $<.001$ \\
\hline \multicolumn{5}{|l|}{ 17: Percentage of infections prevented by good hand hygiene } & $<.001$ \\
\hline $0 \%-50 \%$ & $98(36.6)$ & $122(19.7)$ & $41(29.3)$ & $261(25.4)$ & \\
\hline $51 \%-70 \%$ & $127(47.4)$ & $265(42.7)$ & $52(37.1)$ & $444(43.2)$ & \\
\hline$>70 \%$ & $43(16.0)$ & $234(37.7)$ & $47(33.6)$ & $324(31.5)$ & \\
\hline \multicolumn{6}{|l|}{ Normative } \\
\hline 18: Hand hygiene is a top priority for hospital senior management & $65(24.1)$ & $196(31.3)$ & $43(30.9)$ & $304(29.4)$ & .074 \\
\hline 19: Colleagues' adherence is good & $84(31.6)$ & $345(55.4)$ & $85(61.6)$ & $514(50.1)$ & $<.001$ \\
\hline 20: Superiors expect adherence & $129(48.5)$ & $448(72.0)$ & $110(78.0)$ & $687(66.8)$ & $<.001$ \\
\hline 21: Colleagues expect adherence & $105(39.3)$ & $399(64.0)$ & $92(65.7)$ & $596(57.9)$ & $<.001$ \\
\hline 22: Patients expect adherence & $190(71.0)$ & $466(74.8)$ & $104(74.3)$ & $760(73.7)$ & .5 \\
\hline 23: Person believed to be most influential expects adherence & $145(56.0)$ & $444(73.3)$ & $98(73.7)$ & $687(68.8)$ & $<.001$ \\
\hline 24: Adherence models good practices for others & $150(55.6)$ & $345(56.0)$ & $90(64.8)$ & $585(57.1)$ & .144 \\
\hline \multicolumn{6}{|l|}{ Control } \\
\hline 25: Hand hygiene is relatively easy to perform & $145(54.5)$ & $414(66.2)$ & $111(79.9)$ & $670(65.1)$ & $<.001$ \\
\hline
\end{tabular}

vere consequences for patients. A greater percentage of physicians, compared with nurses and nursing assistants, believed that more than $5 \%$ of patients with a healthcare-associated infection will die from their infection.

Perception of a positive safety climate with respect to hand hygiene was higher among nurses, and a total of $31.3 \%$ of nurses considered hand hygiene to be a top safety priority for senior hospital management (question 18), compared with $24.1 \%$ of physicians and $30.9 \%$ of nursing assistants. Patients' expectations had the greatest influence on HCWs' normative beliefs, with no significant difference observed across professional categories. However, compared with respondents in the other professional groups, physicians reported less social pressure from superiors, colleagues, and individuals perceived to be influential. No significant difference was found among professional groups with respect to respondents' perception of the impact of their own hand hygiene behavior on that of their colleagues (question 24). Perceived self-efficacy was greatest among nurses, followed by nursing assistants and physicians.

The median overall self-reported rate of adherence to hand hygiene guidelines was $90 \%$ (interquartile range [IQR], $80 \%$ $90 \%$ ) on a $10 \%$ stepwise scale. Physicians estimated their rate of hand hygiene adherence to be $80 \%$ (IQR, 70\%-90\%), nurses estimated their rate of adherence to be $90 \%$ (IQR, $80 \%-90 \%$ ), and nursing assistants estimated their rate of adherence to be $90 \%$ (IQR, $80 \%-100 \%$ ). A declared adherence rate of $80 \%$ or greater was more common among nursing assistants (86.4\% [121]) and nurses (85.7\% [535]) than among physicians $(69.2 \%[184])(P<.001)$.

The internal and external factors associated with a high self-reported adherence rate (ie, self-reported performance of proper hand hygiene during $80 \%$ or more of hand hygiene opportunities) are listed in Table 2. Multivariate analysis iden- 
TABLE 2. Variables Associated With a High Self-Reported Rate of Hand Hygiene Adherence, University of Geneva Hospitals, October 2005

\begin{tabular}{|c|c|c|c|c|c|}
\hline \multirow[b]{2}{*}{ Variable, question item } & \multirow{2}{*}{$\begin{array}{c}\text { No. }(\%) \text { of } \\
\text { respondents } \\
\text { who reported } \\
\text { good adherence }\end{array}$} & \multicolumn{2}{|c|}{ Univariate analysis } & \multicolumn{2}{|c|}{ Multivariate analysis } \\
\hline & & RR (95\% CI) & $P$ & OR $(95 \% \mathrm{CI})$ & $P$ \\
\hline \multicolumn{6}{|l|}{ Demographic characteristic } \\
\hline 1: Male sex & $201 / 815(24.7)$ & $1.2(1.1-1.3)$ & $<.001$ & $0.6(0.4-0.98)$ & .041 \\
\hline 2: Age $>40$ years & $363 / 838(43.3)$ & $1.0(0.9-1.1)$ & .97 & $\ldots$ & $\ldots$ \\
\hline 4: Junior staff member & $619 / 783(79.1)$ & $1.2(1.1-1.3)$ & $<.001$ & ... & ... \\
\hline $6:>10$ years experience at this institution & $341 / 838(41.0)$ & $1.1(1.0-1.1)$ & .02 & $\ldots$ & $\ldots$ \\
\hline 8: Receipt of structured training in hand hygiene & $632 / 834(75.8)$ & $1.0(0.9-1.7)$ & .9 & $1.7(1.1-2.7)$ & .020 \\
\hline 9: Participation in previous hand hygiene campaign(s) & $645 / 826(78.1)$ & $1.1(0.9-1.2)$ & .07 & $1.7(1.0-2.7)$ & .046 \\
\hline 11: Hand hygiene adherence observed in 2005 & $170 / 830(20.5)$ & $1.0(0.9-1.1)$ & .5 & $\ldots$ & ... \\
\hline \multicolumn{6}{|l|}{ Behavioral belief } \\
\hline 15: Healthcare-associated infections are severe for patients & $278 / 833(33.4)$ & $1.1(1.0-1.2)$ & .07 & $\cdots$ & - \\
\hline 16: Hand hygiene effectively prevents infections & $735 / 837(87.8)$ & $1.2(1.0-1.3)$ & .002 & $\ldots$ & $\ldots$ \\
\hline \multicolumn{6}{|l|}{ Normative belief } \\
\hline 18: Hand hygiene is a high priority for senior management & $768 / 837(91.8)$ & $1.3(1.1-1.5)$ & $<.001$ & $\ldots$ & $\cdots$ \\
\hline 19: Colleagues' adherence is perceived as good & $485 / 829(58.5)$ & $1.4(1.3-1.5)$ & $<.001$ & $5.3(3.0-9.1)$ & $<.001$ \\
\hline 20: Superiors expect adherence & $599 / 831(72.1)$ & $1.3(1.2-1.4)$ & $<.001$ & $\ldots$ & $\ldots$ \\
\hline 21: Colleagues expect adherence & $537 / 834(64.4)$ & $1.3(1.2-1.4)$ & $<.001$ & $1.8(1.0-3.2)$ & .042 \\
\hline 22: Patients expect adherence & $644 / 834(77.2)$ & $1.2(1.1-1.3)$ & $<.001$ & $\ldots$ & ... \\
\hline 23: The person perceived as most influential expects adherence & $605 / 808(74.9)$ & $1.3(1.2-1.5)$ & $<.001$ & $\ldots$ & ... \\
\hline 24: Adherence models good practices for others & $504 / 825(61.1)$ & $1.2(1.1-1.3)$ & $<.001$ & ... & ... \\
\hline \multicolumn{6}{|l|}{ Control belief } \\
\hline 25: Hand hygiene is relatively easy to perform & $614 / 838(73.3)$ & $1.5(1.4-1.6)$ & $<.001$ & $7.1(4.5-11.0)$ & $<.001$ \\
\hline
\end{tabular}

NOTE. Good hand hygiene adherence was defined as self-reported performance of proper hand hygiene during $80 \%$ or more of hand hygiene opportunities. $\mathrm{CI}$, confidence interval; OR, odds ratio; RR, relative risk.

tified the following independently associated factors: female sex, previous training in hand hygiene, participation in a hand hygiene campaign, the expectations of colleagues, perceived good adherence in colleagues, and a perception that relatively little effort was required to perform hand hygiene.

In the separate models for the 3 professional categories, strong control beliefs and strong normative beliefs were the most consistent explanations for self-reported good adherence (Table 3). The belief that relatively little effort was required to perform hand hygiene was the strongest independent predictor across all HCW categories. Perceived patient expectations appear to motivate physicians in particular, whereas nurses are very responsive to training and campaign exposure.

\section{DISCUSSION}

Consistent with the long-standing history of successful hand hygiene promotion at our institution, ${ }^{2,12,20,21}$ most respondents reported having been exposed to hand hygiene promotion and training and several to direct observation of compliance. Behavioral beliefs in favor of hand hygiene seemed to be very strong. Respondents generally judged the frequency, severity, and impact of healthcare-associated infections to be greater

TABLE 3. Independent Explanatory Factors for Self-Reported Good Hand Hygiene Adherence in Models for 3 Professional Categories, University of Geneva Hospitals, October 2005

\begin{tabular}{lccc}
\hline Variable, question item & Physicians & Nurses & Nursing assistants \\
\hline $\begin{array}{l}\text { Demographic characteristic } \\
\text { 8: Receipt of structured training in hand hygiene }\end{array}$ & $\ldots$ & $3.0(1.5-5.9)$ & $\ldots$ \\
9: Participation in previous hand hygiene campaign(s) & $\ldots$ & $2.2(1.0-4.6)$ & $\ldots$ \\
Normative belief & & & \\
19: Colleagues' adherence is perceived to be good & $3.3(1.4-7.9)$ & $5.4(2.4-12.1)$ & $5.9(1.3-27.4)$ \\
22: Patients expect adherence & $3.5(1.6-8.0)$ & $\ldots$ & $\ldots$ \\
Control belief & & & \\
25: Hand hygiene is relatively easy to perform & $5.0(2.4-10.4)$ & $12.1(5.8-24.98)$ & $11.9(2.0-72.0)$ \\
\hline
\end{tabular}

NOTE. Good hand hygiene adherence was defined as self-reported performance of proper hand hygiene during $80 \%$ or more of hand hygiene opportunities. 
than that suggested by published surveillance data and even greater than findings from surveillance conducted in our own hospital. Moreover, the perceived benefit of hand hygiene was quite great among HCWs in our institution; almost $75 \%$ believed that good hand hygiene could prevent at least 50\% of healthcare-associated infections. From a societal marketing perspective, hand hygiene has a high profile as a product and is considered a powerful patient-safety tool by potential consumers. ${ }^{22}$ This correlates well with respondents' strong appreciation for the safety climate at our institution; almost $30 \%$ of all HCWs surveyed considered hand hygiene to be among the chief executive officer's prime priorities for enhancing patient safety.

As a further determinant of the intention to comply, ${ }^{16}$ normative beliefs were also favorable with respect to hand hygiene, and well over half of the respondents perceived high expectations in this regard from their superiors, colleagues, and, even more so, from patients. The important impact of role models has been shown with students, whose adherence was strongly influenced by their mentors' attitude at the bedside. $^{23}$ This aspect has been strongly emphasized in a previous study among physicians at our institution. ${ }^{7,18}$ Of interest, patient expectations are apparently a strong motivation for HCWs' performance of hand hygiene. ${ }^{24-26}$ Patient empowerment has not been explicitly promoted in our institution, but on the basis of these results, we are now investigating ways to do so in the future.

The third component that determined intention to comply with good hand hygiene practices was control beliefs, which we assessed in terms of HCWs' perception of the amount of effort needed to perform hand hygiene. The belief that hand hygiene required relatively little effort was consistently associated with good adherence. This probably reflects the widespread availability and acceptance of alcohol-based hand rub at the point of care in our institution, in the form of pocketsized bottles carried by staff members. ${ }^{7}$ The introduction of hand rub in this form was clearly associated with increased adherence some 10 years earlier at our institution, ${ }^{2}$ and hand rub consumption per patient-day has increased continuously ever since. ${ }^{12}$

Interestingly, the key perception of the basic problemhealthcare-associated infections-and the perceived high efficacy of the solution-hand hygiene-were not independently associated with a high self-reported rate of adherence in the overall multivariate model or in the individual models for physicians or nurses. HCWs seem much more driven by normative beliefs (ie, perceived social pressure) and control beliefs (ie, perceived easiness of the task) than by beliefs about infections and their prevention. The same phenomenon was previously reported among nurses in charge of neonates in our institution. ${ }^{18}$ We argue that a highly repetitive task, such as hand hygiene, can be habit-forming, and the reason to perform it may become less important than the related practical issues and the emulation of peers.

Another possible explanation could be that the questions about beliefs in our questionnaire (and other survey instru- ments) restricted health outcome beliefs to those regarding patients; that is, they did not include the respondents' beliefs about himself or herself. The latter beliefs might have a stronger impact on hand hygiene behavior. This hypothesis is supported by the observation that hand hygiene is more willingly performed after patient contact or aseptic procedures, rather than before contact, which would be more effective for the patient. $^{2}$ Others found that HCWs' beliefs about negative outcomes for themselves influenced their behavior just as strongly as their beliefs about negative patient outcomes. ${ }^{27}$

Furthermore, we found that more basic factors, such as female sex, have an independent impact on HCWs' reported intention to perform well. Sex might, in fact, confound many of the reported results of nurses performing better in hand hygiene than physicians (who are often predominantly male), but this factor has rarely been investigated as a predictor of hand hygiene adherence. ${ }^{28}$ This issue might merit greater attention in future research and would probably correspond to requirements for market segmentation in a promotional marketing campaign. ${ }^{29}$

Cognitive behavior models have previously been used to explain hand hygiene behavior. ${ }^{18,30,31}$ In a study based on the Theory of Planned Behavior, O'Boyle et al. ${ }^{27}$ found a low correlation between self-reported and observed compliance. The latter was more strongly determined by actual workload on the ward at the time of observation. Using structural equation modeling, they succeeded in fitting a highly predictive model for the HCWs' intention to adhere to well-defined hand hygiene guidelines. ${ }^{27}$ As in the present study, control beliefs were the most prominent predictors of intention to adhere to good hand hygiene practices.

Pessoa-Silva et al. ${ }^{18}$ used a questionnaire derived from the Theory of Planned Behavior derived to evaluate the motivational factors associated with self-reported hand hygiene behavior in a neonatal intensive care unit prior to a promotional intervention. Multiple logistic regression was used to evaluate proximal components for their prediction of selfreported optimal hand hygiene adherence, including the following: attitude toward hand hygiene, the perceived ease of complying with hand hygiene, subjective norms, the behavioral norm, adequate perception of risk of transmission, and motivation. After summing the scale results by type of hand hygiene indication and transformation in binary variables, a logistic regression model was used to explain self-reported adherence. Not unlike the findings in the present study, intention to comply was associated with perceived control over hand hygiene and a positive perception of how much superiors valued hand hygiene.

Pittet et al. ${ }^{7}$ employed individual observations as well as a questionnaire containing elements of the Theory of Planned Behavior to evaluate determinants of physicians' hand hygiene behavior. They used a multivariate logistic regression model to relate the intention to adhere, the perception of knowledge about hand hygiene indications, the attitude toward hand hygiene, the perceived behavioral norm, the perceived subjective norm, the perceived difficulty of adherence, 
the perceived risk for cross-transmission, and motivation as independent variables, in addition to other demographic characteristics and external factors. The awareness of being observed, the belief that one is a role model, and a positive attitude towards hand hygiene after patient contact were the cognitive factors that were independently associated with good observed hand hygiene performance.

Recently, Whitby et al. ${ }^{31}$ used the Theory of Planned Behavior to explain inherent and elective hand hygiene behavior in 2 different populations, HCWs and individuals in the community. They applied multivariate linear regression modeling with scales summed per cognitive construct. Community behavior, attitudes, perceived peer behavior, subjective norms, and perceived effort involved in the elective in-hospital intention to wash one's hands independently explained $64 \%$ of elective in-hospital hand washing events. In contrast to our findings, all 3 proximal components of the Theory of Planned Behavior were independently associated with intention to adhere. Conversely, behavioral control was only weakly linked to the intention to perform hand washing. Importantly, however, facilitated action by systematic recourse to the use of alcohol-based hand rub was not studied. The disparity in study populations, types of question, analytical methods, and primary objectives with respect to these 4 studies-in addition to the present study-is substantial enough to at least partially explain the differences in study outcome and render comparison futile.

The most important limitation of our survey is that it did not measure respondents' actual adherence to hand hygiene practices. However, according to cognitive behavior models, self-reported adherence is an accepted surrogate because of the cost of large-scale observations and problems with the confidentiality of the results. ${ }^{16}$ Moreover, as we converted selfreported adherence into a binary variable, subtler bias was probably eliminated. Self-reports are known to overestimate true adherence rates. ${ }^{27,32}$ Ordinal differences between professional categories, however, were consistent with published data, a fact that strengthens the assumed link between selfreports and actual performance of the task. Moreover, selfreports predicted observed adherence in an earlier study conducted at our institution.?

The response rate was reasonably good (35.2\%). Hence, responder bias remains a worrisome possibility. Self-administration of the questionnaire might have distorted the results towards more socially acceptable opinions and behavior. The fact that this survey was anonymous should, however, have limited this bias.

Finally, the results of our study are limited to a single institution with a very specific past experience of repeated hand hygiene campaigns. This clearly limits the applicability of the results to a wide range of settings. Our situation might, however, become more widespread, given the current ongoing promotional activity worldwide. . $^{33,34}$

In conclusion, behavioral, normative, and control beliefs were strongly in favor of hand hygiene at our institution, but only the normative beliefs (ie, perceived expectations regard- ing hand hygiene adherence) and the control beliefs (ie, perceived effort involved in hand hygiene) were independently associated with good adherence in the overall population. Additionally, female sex, receipt of training, and perception of campaign exposure further explained a high self-reported rate of adherence. Among physicians, patients' expectations were an additional independent contributor to self-reported good adherence rates. These findings add to the accumulating body of literature showing that interventions should be multimodal and include facilitated access to tools for hand hygiene (ie, alcohol-based hand rub) at the point of care. Finally, one of the major research challenges in this area is to develop and validate a mathematical model in which the rate of selfreported adherence can be used to estimate the rate of actual adherence.

\section{ACKNOWLEDGMENTS}

We thank Rosemary Sudan, for her much appreciated editorial work; the healthcare workers of the University of Geneva Hospitals, who made time in their busy schedules to complete the questionnaire; and Nadia Colaizzi, Miriam Ganzfried, and François Eggimann, for practical contributions to this study.

Potential conflicts of interest. All authors report no conflicts of interest relevant to this article.

Address reprint requests to Didier Pittet, MD, MS, Infection Control Program, University of Geneva Hospitals, 24 Rue Micheli-du-Crest, 1211 Geneva 14, Switzerland (didier.pittet@hcuge.ch).

\section{REF E R E N C E S}

1. World Health Organization (WHO). WHO Guidelines on Hand Hygiene in Health Care (Advanced Draft). Geneva: World Health Organization; 2006.

2. Pittet D, Hugonnet S, Harbarth $S$, et al. Effectiveness of a hospital-wide programme to improve compliance with hand hygiene. Lancet 2000; 356:1307-1312.

3. Whitby M, Pessoa-Silva CL, McLaws ML, et al. Behavioural considerations for hand hygiene practices: the basic building blocks. J Hosp Infect 2007; 65:1-8.

4. Stone S, Teare L, Cookson B. Guiding hands of our teachers. Handhygiene Liaison Group. Lancet 2001; 357:479-480.

5. Ajzen I. Attitudes, Personality and Behavior. 2nd ed. Maidenhead, UK: McGraw-Hill; 2005.

6. Kretzer EK, Larson EL. Behavioral interventions to improve infection control practices. Am J Infect Control 1998; 26:245-253.

7. Pittet D, Simon A, Hugonnet S, Pessoa-Silva CL, Sauvan V, Perneger TV. Hand hygiene among physicians: performance, beliefs, and perceptions. Ann Intern Med 2004; 141:1-8.

8. World Health Organization. The first Global Patient Safety Challenge. Available at: http://www.who.int/gpsc/en/. Accessed July 3, 2007

9. Pittet D, Mourouga P, Perneger TV. Compliance with handwashing in a teaching hospital. Ann Intern Med 1999; 130:126-130.

10. Johnson PD, Martin R, Burrell LJ, et al. Efficacy of an alcohol/chlorhexidine hand hygiene program in a hospital with high rates of nosocomial methicillin-resistant Staphylococcus aureus (MRSA) infection. Med J Aust 2005; 183:509-514.

11. Storr J. The effectiveness of the national Clean Your Hands campaign. Nurs Times 2005; 101:50-51.

12. Pittet D, Sax H, Hugonnet $S$, Harbarth $S$. Cost implications of successful hand hygiene promotion. Infect Control Hosp Epidemiol 2004; 25 : 264-266. 
13. Conner M, Norman P. Predicting Health Behaviour: Research and Practice With Social Cognition Models. Buckingham, UK: Open University Press; 1995.

14. Godin G, Kok G. The theory of planned behavior: a review of its applications to health-related behaviors. Am J Health Promot 1996; 11: 87-98.

15. Sheeran P, Conner M, Norman P. Can the theory of planned behavior explain patterns of health behavior change? Health Psychol 2001; 20: 12-19.

16. Ajzen I. Attitudes, Personality, And Behavior: A Review of its Applications to Health-Related Behaviors. Buckingham, UK: Open University Press; 1988.

17. Sax H, Perneger T, Hugonnet S, Herrault P, Chraiti MN, Pittet D. Knowledge of standard and isolation precautions in a large teaching hospital. Infect Control Hosp Epidemiol 2005; 26:298-304.

18. Pessoa-Silva CL, Posfay-Barbe K, Pfister R, Touveneau S, Perneger TV, Pittet $\mathrm{D}$. Attitudes and perceptions toward hand hygiene among healthcare workers caring for critically ill neonates. Infect Control Hosp Epidemiol 2005; 26:305-311.

19. Jaccard J, Weber J, Lundmark J. A multitrait-multimethod analysis of four attitude assessment procedures. J Experiment Social Psy 1975; 11 : 149-154.

20. Pittet D, Stephan F, Hugonnet S, Akakpo C, Souweine B, Clergue F. Hand-cleansing during postanesthesia care. Anesthesiology 2003;99: 530-535.

21. Hugonnet S, Perneger TV, Pittet D. Alcohol-based handrub improves compliance with hand hygiene in intensive care units. Arch Intern Med 2002; 162:1037-1043.

22. Gopal Rao G, Jeanes A, Osman M, Aylott C, Green J. Marketing hand hygiene in hospitals-a case study. J Hosp Infect 2002; 50:42-47.

23. Snow M, White GL Jr, Alder SC, Stanford JB. Mentor's hand hygiene practices influence student's hand hygiene rates. Am J Infect Control 2006; 34:18-24.

24. McGuckin M, Waterman R, Storr IJ, et al. Evaluation of a patientempowering hand hygiene programme in the UK. J Hosp Infect 2001; 48:222-227.

25. McGuckin M, Porten LL. Handwashing education practices: a descriptive survey. Clin Perform Qual Health Care 1999; 7:94-96.

26. McGuckin M, Waterman R, Porten L, et al. Patient education model for increasing handwashing compliance. Am J Infect Control 1999; 27: 309-314.

27. O'Boyle CA, Henly SJ, Larson E. Understanding adherence to hand hygiene recommendations: the theory of planned behavior. Am J Infect Control 2001; 29:352-360.

28. van de Mortel T, Bourke R, McLoughlin J, Nonu M, Reis M. Gender influences handwashing rates in the critical care unit. Am J Infect Control 2001; 29:395-399.

29. Smith WA. Social marketing: an overview of approach and effects. Inj Prev 2006; 12(suppl 1):i38-i43.

30. Pittet D. The Lowbury lecture: behaviour in infection control. J Hosp Infect 2004; 58:1-13.

31. Whitby M, McLaws ML, Ross MW. Why healthcare workers don't wash their hands: a behavioral explanation. Infect Control Hosp Epidemiol 2006; 27:484-492.

32. Jenner EA, Fletcher BC, Watson P, Jones FA, Miller L, Scott GM. Discrepancy between self-reported and observed hand hygiene behaviour in healthcare professionals. J Hosp Infect 2006; 63:418-422.

33. Pittet $D$, Donaldson L. Clean care is safer care: a worldwide priority. Lancet 2005; 366:1246-1247.

34. Pittet D, Donaldson L. Clean care is safer care: the first global challenge of the WHO World Alliance for Patient Safety. Infect Control Hosp Epidemiol 2005; 26:891-894. 